\section{UC works to monitor, prevent, contain avian flu}

Since an outbreak of virulent avian flu, H5N1, Semerged in Southeast Asia in 2003, the disease has spread to wild and domestic birds on three continents. Close to 150 million birds have died or been destroyed as a result, according to the World Health Organization (WHO).

The disease spread to bird populations in Africa in February 2006, and moved into Europe at about the same time (see map). Circumstantial evidence indicates that migratory birds had introduced a low pathogenic form of avian flu into poultry flocks, where it then mutated into a highly pathogenic form, according to WHO sources.

"While there have been no documented cases of avian influenza in North American birds, there is a $90 \%$ probability that the Asian strain will eventually be introduced into California bird populations," says Scott Layne, epidemiologist at UCLA's School of Public Health.

Although human cases are extremely rare, as of June 20, 228 people in Asia, Europe and Africa had contracted the disease, and all were in close contact with infected birds. Of the humans infected 130 died, for a mortality rate of over $50 \%$.

According to the WHO, which monitors avian flu globally, the disease is not passed from human to human at present. However, each new human case slightly increases the chance of a viral mutation leading to a form of influenza that could be passed easily from human to human.

UC scientists at campuses, medical centers and Cooperative Extension offices statewide have been working to address the causes, risk factors and pre-

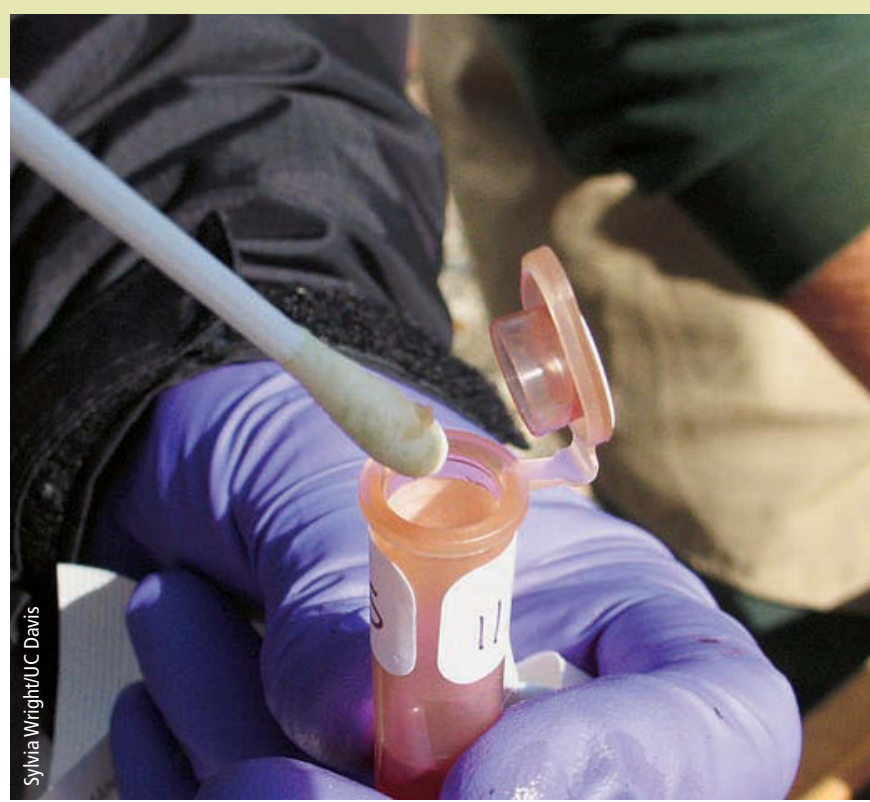

UC researchers conduct tests daily for avian influenza, which has not yet been documented in North American birds.

vention of avian influenza in humans and birds (for a sampling of systemwide efforts, see box).

\section{Detection and response}

"California's front line of defense is surveillance, detection and containment, should disease be found," says Francine Bradley, UC Davis Cooperative Extension poultry specialist. While the new pathogenic strain of avian flu poses a remote hazard to Californians at present, it raises a plausible threat to California's egg and poultry industries (worth more than $\$ 1$ billion in 2004), game species, wildlife, and backyard or other birds. By monitoring for the presence of diseased birds, UC experts aim to protect avian populations and reduce the virus's potential to mutate into an influenza pandemic in people.

Poultry farmers and other bird owners who find signs of illness in domestic or wild birds have a legal obligation to report it to state authorities

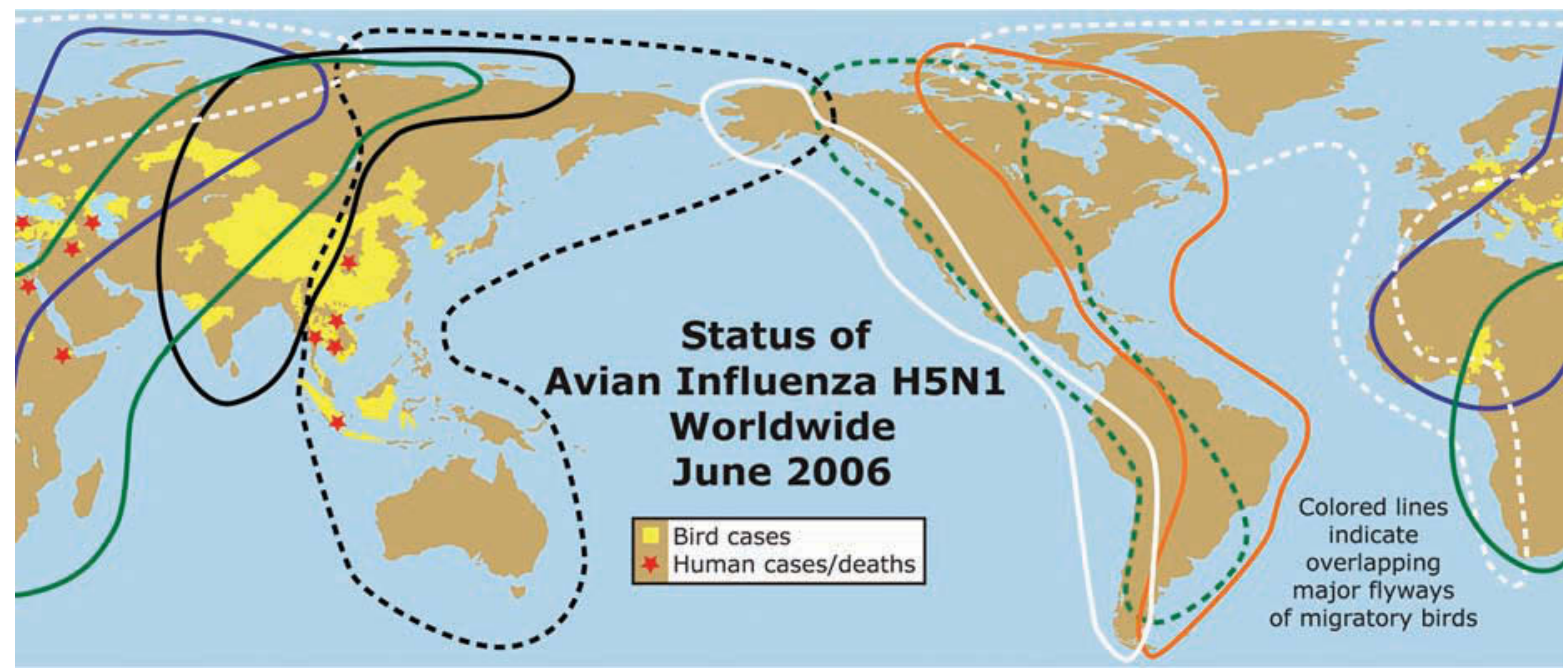

The current outbreak of avian flu H5N1 began in Asia in 2003 and has spread west and south, infecting people in 10 countries. Sources: avian influenza outbreaks: WHO, OIE, FAO and government sources; flyways: Wetlands International. 


\section{More avian flu research at UC}

The UCLA Center for Vaccine Research is conducting clinical testing of a bird flu vaccine. It is one of three sites nationwide selected by the National Institute of Allergy and Infectious Diseases, part of the National Institutes of Health, to conduct such testing.

UC Cooperative Extension advisers are working with large and small poultry producers to develop detection and prevention strategies for an avian flu infection, recognizing the major economic impact the disease could have on California's poultry industry.

Lawrence Livermore National Laboratory researchers are working to develop and deploy a multiplex diagnostic for a wide range of respiratory problems, including different types of influenza; working to identify potential new signatures for multiple types of influenza viruses; and developing rapid methods for the analysis of viral genomes, including the possible mutation of avian influenza.

A team led by UC Irvine evolutionary biologist Robin Bush will receive $\$ 1.5$ million over the next 5 years to develop computer-based simulations of pandemic flu and other infectious disease outbreaks. The research could help officials better understand how to prepare for and contain the spread of such diseases.

At UC Davis Medical Center, physicians are providing medical education and training for health practitioners to plan, recognize and test for cases of avian influenza in people, and putting in place procedures to deal with a possible outbreak of avian influenza.

UC San Diego Extension administers the California Office of Binational Border Health, which is working with the California Department of Health Services to address preparedness for a pandemic influenza in the California-Baja California border region.

UC faculty are working to help inform state decision-makers. When the state Assembly called a hearing recently on California's preparation for avian flu, UCLA associate professor Scott Layne provided expert testimony on the origins and potential threats of the disease.

The San Diego Supercomputer Center at UC San Diego is part of an international research effort that is using a computational data grid to study the mechanism of viral resistance to the human immune defense, provide an international data repository for different strains of avian flu, and identify new leads for drug development and screening.

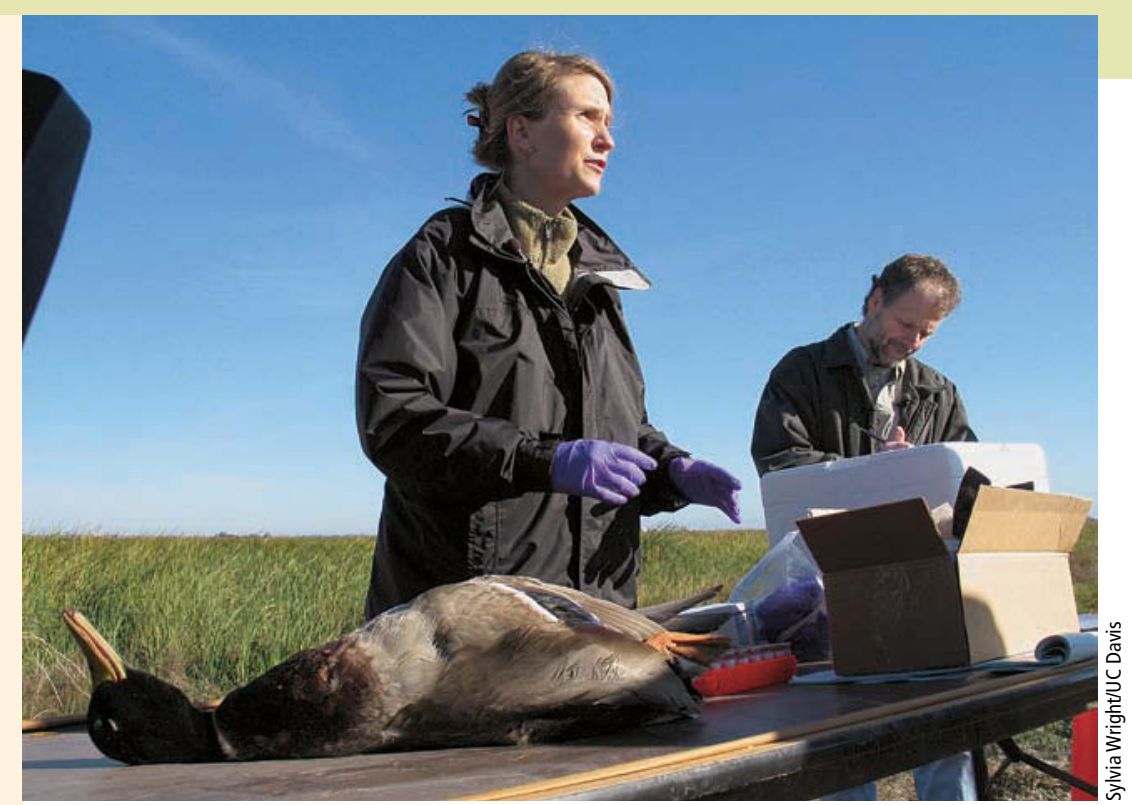

for testing. The five laboratories of the California Animal Health and Food Safety Laboratory System monitor poultry statewide for avian influenza virus and other infectious disease organisms. Testing is conducted on flocks and individual birds every day. UC Davis School of Veterinary Medicine faculty are based at these laboratories (funded by the California Department of Food and Agriculture [CDFA]) in Davis, Turlock, Tulare, Fresno and San Bernardino. In addition, "veterinary investigators are developing new methods to sample airborne viruses and rapidly identify and respond to viral outbreaks," Bradley says.

Researchers at the UC Davis Wildlife Health Center are participating in a nationwide surveillance effort focusing on wild birds of the Pacific Flyway, testing for the presence of avian influenza infection. Sampling and virologic testing are under way in a wide variety of bird species, and duck hunters are cooperating in this effort.

\section{Industry and producer education}

With support from CDFA, Bradley and Carol Cardona of UC Davis Veterinary Medicine Extension instituted the Poultry Health Inspection Program to train inspectors at the 73 county, district and State Fair poultry shows. Experts have so far trained 148 poultry health inspectors, and they communicate regularly with fair managers.

The Game Fowl Health Assurance Program, coordinated by Bradley and CDFA veterinarian David Castellan, aims to reach a small but influential group of breeders. The program stresses biosecurity, surveillance for a variety of poultry diseases, including avian influenza, and vaccinations where appropriate. Though a small program, all poultry groups benefit, Bradley says. "We have some good sentinels in place."

Furthermore, Bradley's youth poultry program - continued on page 112
Terra Kelly, doctoral student at UC Davis School of Veterinary Medicine, and Walter Boyce, director of the UC Davis Wildlife Health Center, explain how wild birds are tested for avian influenza. 
- continued from page 111

trains 4-H members and other young poultry enthusiasts to keep their birds healthy. "Children don't take long to really get it," about good sanitation and protecting their birds, Bradley says.

Cardona and UC Davis veterinary professors Sharon Hietala and Tim Carpenter are also mounting a program to improve surveillance and security strategies in live bird markets that sell poultry to restaurants and consumers of traditional ethnic foods. Cardona conducts virus research at the school and also acts as a liaison with racing pigeon hobbyists and other bird owners. Clinicians at the UC Davis Veterinary Medical Teaching Hospital also work with owners of pet birds, including exotics.

\section{Media and public outreach}

Boyce, Cardona and UC Davis School of Medicine faculty members Christian Sandrock and Warner Hudson established a tightly knit team that has coordinated outreach efforts to inform the public about the many aspects of avian influenza and public-health emergency preparedness. These experts call their approach "Connection through Protection." Since September 2005, they have briefed legislators, hosted news conferences and public events, and responded to hundreds of calls from the news media.

"People can prevent flu by taking basic sanitary precautions such as hand-washing and staying home when sick," Sandrock says. "Humans must be vigilant, too, because people may be as likely as birds to introduce the virus, by unwittingly or illegally exposing healthy birds to sick animals."

The quartet is developing a "Flu School" training program that will enable others - including alumni of the UC Davis Master of Preventive Veterinary Medicine program working in 75 countries - to conduct informational workshops throughout the world. - Lynn Narlesky and Editors

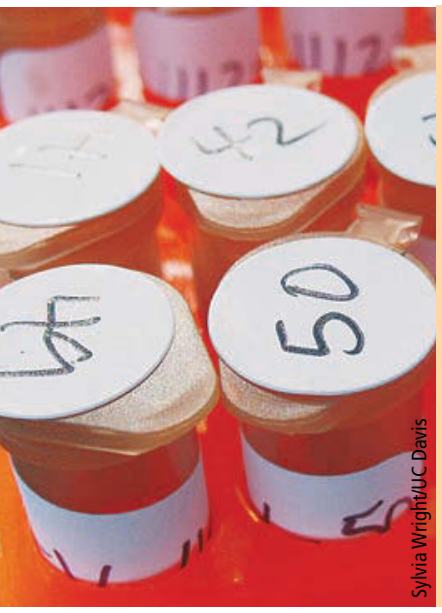

\section{Research seeks to adapt conservation tillage for California fields}

$\Delta S$ agricultural profit margins get smaller and 10 environmental regulations get tighter, California farmers may find relief with conservation tillage. This practice entails fewer tractor passes and so reduces the costs of fuel and labor, as well as emissions of greenhouse gases and nonpoint source pollution to air and water. Common in the Midwest, conservation tillage is relatively new to California, and UC researchers are working to adapt it to local crops and conditions.

"California agriculture is more intensive than in the Midwest, which is primarily grain crops and is thus more amenable to conservation tillage," says UC Davis soil scientist William Horwath. "Here we have many varied crops requiring specific agronomic practices. It's not a clear-cut decision, and it may not be for everyone."

Horwath is part of the Conservation Tillage Workgroup, which was established by the UC Division of Agriculture and Natural Resources in the late 1990s. Today the workgroup has nearly 500 members from UC, government agencies, farmers and environmental organizations; and more than 60 research and demonstration sites statewide. Adopted in the Midwest in the 1930s to control soil erosion, conservation tillage traditionally includes a range of practices, from no tillage at all ("no-till") to strip-till, which leaves at least $30 \%$ of the field covered with crop stubble after harvest. However, because erosion and thus crop residues are less of a concern in California, the workgroup is also evaluating practices that simply reduce tractor passes.

\section{Reducing tractor passes}

Traditional conservation tillage has considerable promise for some California agricultural operations. Tillage to prepare seed beds and control weeds typically accounts for more than one-fifth of production costs on Central Valley farms, according to Jeff Mitchell, a UC Cooperative Extension (UCCE) cropping systems specialist based at the Kearney Agricultural Center in Parlier, who also directs the Conservation Tillage Workgroup. Central Valley farms average 10 soil-preparation operations involving heavy equipment per year, and reducing the number of tillage operations can mean big decreases in both diesel use and dust production. For example, $\mathrm{UC}$ research has shown that conservation tillage decreases fuel use by up to $60 \%$ in back-to-back cotton crops in the San Joaquin Valley (see page 140). 